\title{
Assessing the research and education needs of the organic dairy industry in the northeastern United States
}

\author{
A. B. D. Pereira, ${ }^{*}$ A. F. Brito, ${ }^{*}$ L. L. Townson, $\dagger$ and D. H. Townson $\ddagger^{1}$ \\ *Department of Biological Sciences, \\ †Cooperative Extension, and \\ ‡Department of Molecular, Cellular and Biomedical Sciences, University of New Hampshire, Durham 03824
}

\begin{abstract}
Demographic and management data about organic dairies have been reported previously, but the current study is the first needs assessment of research and educational priorities of organic dairy farmers in the northeastern United States based directly upon their input. Our objectives were to (1) develop an initial understanding of the emerging research and educational needs of organic dairy farmers in the northeastern United States via focus group interviews, and (2) prioritize the needs identified by the focus groups with a broader population of organic dairy farmers via survey methods. Focus group interviews determined the questions used for the survey questionnaire distributed to 1,200 members of the Northeast Organic Dairy Producers Alliance. The members were asked about demographic information, but more importantly, challenges concerning business management and marketing, organic certification, and animal nutrition, health, and reproduction. The results (183 respondents, $15 \%$ response rate) were parsed by region (New England farms compared with New York and Pennsylvania farms), herd size (i.e., 12 to 37,38 to 59 , and $>60$ cows), and years of organic certification ( $<4$ yr vs. $\geq 4$ yr); however, no differences between regions were observed for demographic data. The average farm consisted of 309 acres and 57 milking cows, on which most of the forage was homegrown but grains were purchased ( $73 \%$ of farms). Among the greatest challenges identified by the farmers were obtaining a steady, fair price for milk (85\% respondents); determining dry matter intake for animals on pasture $(76 \%)$; and controlling nuisance flies (89\%). Needs for additional research included organic treatments for mastitis $(92 \%$ respondents), growing forages for organic production (84\%), and developing value-added products (84\%). Farms with $<4$ yr of organic certification were concerned with level of knowledge and experience of local certifiers, whereas organic producers with $\geq 4$ yr of or-
\end{abstract}

Received February 12, 2013.

Accepted August 6, 2013.

${ }^{1}$ Corresponding author: dave.townson@unh.edu ganic certification were more interested in field testing of new organic products. Opportunities for educational programs included learning about direct marketing possibilities (76\% respondents) and providing training to regional veterinarians interested in organic remedies (91\%). In conclusion, the information obtained from the current needs assessment provides a foundation for future research proposals and educational outreach programs, germane to stakeholder needs, which could benefit the organic dairy industry within the region and beyond.

Key words: organic dairy farming, research needs, educational needs, northeastern United States

\section{INTRODUCTION}

The emergence of organic milk production during the last decade as one of the fastest growing segments of organic agriculture in the United States has created new and exciting opportunities for organic dairy farmers in the northeastern United States (hereafter, the Northeast). Demographic and management practices among organic dairy producers have been surveyed and reported (McBride and Greene, 2009; Stiglbauer et al., 2013). However, no formal needs assessment based upon direct input from organic dairy farmers, specifically within the Northeast, has been conducted previously. The majority of dairy farms in the Northeast have fewer than 100 milking cows (McBride and Greene, 2009; Winsten et al., 2010). To improve the economic viability of their operations, some farmers have shifted their conventional operations to organic milk production (Dalton et al., 2008). Between 2000 and 2008, the number of certified organic dairy cows on US farms increased from 38,000 to more than 249,000 cows, an annual average increase of $69 \%$ (USDA-ERS, 2010). Conversely, the total number of milk cows in the United States has declined from approximately 20 million cows in 1950 to fewer than 10 million cows today (USDA-NASS, 2012). The consumer market for organic milk has grown from $2 \%$ to $3 \%$ of total milk consumption between 2006 and 2008, with most of the 
organic milk produced being marketed as fluid milk (Miller and Blayney, 2006). In 2008, national production of organic milk reached approximately 567,000 t of milk, and the trend of growth has continued, following a pattern similar to total milk production (50 million tonnes in 1950 to more than 80 million tonnes today; USDA-NASS, 2012). Despite these encouraging trends, the total number of dairy farms in the Northeast has diminished from more than 100,000 farms in 1960 to fewer than 16,000 farms today (USDA-NASS, 2012). However, more than $80 \%$ of all US certified organic dairies are located in the Northeast and Upper Midwest (McBride and Greene, 2009). For these reasons, future research and educational outreach efforts are needed to assist Northeast organic dairy farmers in managing their operations during difficult economic times. Without question, organic dairy farming has become a viable alternative enterprise, especially for the relatively small northeastern dairy farms that cannot expand to the size necessary to compete in the conventional sector. Marketing of high quality organic milk and dairy products necessitates expanding the learning community to include other representative stakeholders (e.g., organic organizations, cooperatives, and milk processors). However, the first critical step to develop a comprehensive assessment of the research and educational needs of the organic dairy industry in the Northeast is to actively engage organic dairy farmers in these discussions.

The objectives of the current study were to (1) develop an initial understanding of the emerging research and educational needs of organic dairy farmers from the Northeast (New York, Pennsylvania, Massachusetts, New Hampshire, Vermont, and Maine), including the most effective means of communication and outreach, via focus group interviews; and (2) prioritize the research and educational needs identified in the focus groups with a broader population of organic dairy farmers via survey methods.

\section{MATERIALS AND METHODS}

The University of New Hampshire's Institutional Review Board provided review and approval for the study (IRB \#4911), and a consent form, along with University of New Hampshire Human Subjects Compliance Contact information, was provided to participants of the focus groups as well as to those asked to complete surveys. Participants were asked to give consent to be included as research subjects and responses were only included from those who provided consent. All participants were provided with the mailing address, phone number, and email address of the evaluator in case questions arose about the survey or the overall research study.

\section{Focus Group Interviews}

A series of focus group interviews were conducted to obtain a broad perspective of the research needs and issues facing the organic dairy industry in the Northeast. The largest numbers of certified organic dairies in this region are located in Maine, Vermont, New York, and Pennsylvania. For this reason, extension educators and industry personnel in these states were engaged to determine the best location for hosting focus group interviews. Acknowledging that extension educators are keenly aware of the farmers in their area, we asked them to suggest people who would be likely to participate in focus group interviews and yet represent a diverse range of backgrounds (e.g., size of operation, length of time involved in organic dairy production, experience with direct marketing). Each focus group was arranged by the local extension educator, sometimes with input from Organic Valley Family of Farms (Coulee Region Organic Produce Pool Cooperative, La Farge, WI) or the Northeast Organic Dairy Producers Alliance (NODPA, Deerfield, MA). Invitations to participate were sent directly from the local extension educator for 3 separate focus groups in Waterville, Maine; Binghamton, New York; and Randolph, Vermont. Purposeful sampling was used because it is a common method for identifying participants for qualitative inquiry such as focus groups (Seidman, 1998). The extension educators, and Organic Valley and NODPA personnel, however, were not part of the focus group, nor were they present at the time of the focus group interviews. Any concerns about educator- or industry-bias were minimized by the fact that the focus group interviews did not pertain to current extension or dairy industry efforts.

In conducting the focus group interviews, farmers were asked by a professional facilitator to respond to pointed, open-ended questions about their greatest successes, greatest challenges, and the most critical knowledge and skills they felt were needed to be successful in their operations (see Supplemental File A; http:// dx.doi.org/10.3168/jds.2013-6690). In addition, they were asked about their previous experience and future interest in any type of on-farm research. The facilitator was careful to ensure that all participants responded, drawing out shy members when necessary and politely closing off dominant participants when required (Groves et al., 2004). Responses were audio recorded (with permission of participants) to accompany written notes taken by the facilitator and 2 separate note takers. Coding of the qualitative responses was conducted by reading through the written notes taken by the facilitator and note takers as well as the transcripts taken from the audio recordings. This resulted in coding of information into themes. Briefly, the data were summa- 
rized by bracketing and sorting similar comments and phrases, looking for thematic connections (Creswell, 1998). Each transcript was reviewed multiple times (3 or 4) with more detailed sorting occurring during each review. An initial review of the transcripts was used to identify broad themes (e.g., nutrition, marketing, pasture management), whereas subsequent reviews were used to narrow the broader topics into more specific findings (e.g., energy consumption, estimating pasture DMI). The results of each focus group were evaluated separately and then the common themes were identified across all 3 focus groups. The findings were used only to guide the basic outline of the survey questionnaire that was developed and later sent to a much larger population of organic dairy farmers across the Northeast; thus, no statistical analysis was conducted on this information.

\section{Survey Questionnaire}

The data collected from the focus groups guided the development of a survey (see Supplemental File B; http://dx.doi.org/10.3168/jds.2013-6690) with appropriate terminology, common understanding of specific terms, and overall perspectives on a topic (Groves et al., 2004). Three extension educators familiar with the organic dairy industry in the region and all of the research team reviewed the survey to ensure face validity before distribution. Several changes to terminology were made to ensure the questions were clear. The survey (available both as internet-based and print format) was distributed through NODPA to 1,200 NODPA members by an e-mail announcement on NODPA's Listserv and by direct mailing to the membership. A cover letter explaining the aims of the study and providing human subjects compliance information was included with the mail survey along with a postage-paid return envelope addressed to the researchers. The internet survey also contained the same cover letter and human subjects' compliance information. The NODPA membership list was proprietary information of NODPA, which precluded further opportunities to individually track and send follow-up reminders to the nonrespondents of the survey. Specifically, NODPA sent the surveys out on behalf of the researchers. Additionally, returned surveys were received anonymously, so there was no way to exclude those who had already responded from a second mailing or follow-up reminders. We opted not to ask NODPA to send a second mailing in this instance.

The survey questionnaire consisted of questions concerning demographic and descriptive information (i.e., location, years certified as organic, number of cows currently in milk, and acreage of the farm), and other questions asked farmers to rank the most critical issues for their farm in 3 broad areas previously identified from the focus groups: business management and marketing; organic certification requirements and procedures; and animal nutrition, health, and reproduction (see Supplemental File B; http://dx.doi.org/10.3168/ jds.2013-6690). Questions were ranked from being "not a challenge at all" to "a great challenge" on an ascending 4-point Likert scale. Questions were also asked about the importance for additional research and educational programs (Supplemental File B; http://dx.doi. org/10.3168/jds.2013-6690), and were ranked from being "not important" to "very important" in terms of need, again using a 4-point Likert scale. The category "I don't know" was also provided as an option for all survey questions.

Responses by the farmers were initially parsed by region and herd size for comparative purposes. Our rationale was that the Northeast has sufficient spatial heterogeneity in climate, soils, pest populations, and disease incidence to warrant consideration of possible environmental influences (e.g., length of growing season, cold or drought tolerance of forages) on participant responses, some of which became evident during the focus group interviews. We also considered the potential for bias introduced by responses received from states having greater numbers or larger farms (i.e., New York and Pennsylvania) than other states in the Northeast. The 2 regions were New England (NEng), consisting of 77 farms within Maine, New Hampshire, Vermont, and Massachusetts; and New York-Pennsylvania (NY-PA), consisting of 86 farms from these 2 states. We categorized the herds as typical of small, medium-sized, and large farms in the Northeast for comparative purposes, noting that these designations provided relatively equal numbers of farms to consider when evaluating needs assessment endpoints. The designations were as follows: small farms (12 to 37 cows, $\mathrm{n}=51$ farms), medium-sized farms (38 to 59 cows, $\mathrm{n}=52$ farms), and large farms ( $>60$ cows, $n=60$ farms). Farms were also separated according to years certified organic into farms with $<4$ yr of certification ( 35 farms) and those certified for $\geq 4$ yr (124 farms).

\section{Statistical Analyses}

The statistical analyses reported here were performed using SPSS statistical software (SPSS Inc., Chicago, IL). Continuous outcome variables such as years certified organic, cows in milk, and farm acreage were analyzed with descriptive statistics of frequencies. Nonparametric tests of independent samples (KruskalWallis) were used to compare variables between regions and herd size. The Kruskal-Wallis test uses sum of ranks for each group as well as the averages. The ranks 
were based on categories 1 to 4 , where 1 was "not a challenge" or "no need," and 4 was "great challenge" or "very important." The $\alpha$-level of 0.05 was the criterion of significance for all statistical tests. Levels of $0.05<$ $\alpha<0.10$ were considered as trends.

\section{RESULTS AND DISCUSSION}

\section{Focus Group Interviews}

A total of 35 organic dairy farmers (27 males; 8 females) from Maine, Vermont, Pennsylvania, and New York participated in the focus groups hosted at 3 different locations (Waterville, ME; Binghamton, NY; and Randolph, VT). Each focus group consisted of 11 to 12 farmers, all were Caucasian, and the demographics of their operations ranged from 25 to 390 lactating cows, 4 to 11 years certified organic, and 200 to 700 acres. The themes that were identified from the focus group interviews indicated many similarities in challenges and critical knowledge and skills of the participants, in 3 broad areas: (1) business management or marketing; (2) certification requirements and procedures; (3) animal nutrition, health, and reproduction. Focus group interviews offer high face validity (Marshall and Rossman, 1999) and can provide a great deal of descriptive information about a particular set of issues with only a modest number of focus groups (Rossi et al., 2004).

\section{Survey Questionnaire}

One hundred eighty-three surveys were returned from 1,200 surveys distributed through the NODPA member mailing list (15\% response rate). Exclusion criteria included surveys from respondents who were either retired or no longer milking cows (11 respondents), who were organic dairy stakeholders other than farmers (5 respondents), who were not from the Northeast region (1 respondent), or who only partially completed the survey (3 respondents). None of these exceptions were included in the statistical analyses reported herein. Thus, the findings summarized are from 163 of the 183 surveys received. According to USDA-NASS (2012), there are approximately 875 certified organic dairy farms in Maine, New Hampshire, Vermont, Massachusetts, New York, and Pennsylvania, which suggests that the 183 surveys returned may represent a higher response rate $(19 \%)$ than initially thought. However, acknowledging that the current response rate was lower than the desired 60\% (Taylor-Powell and Hermann, 2000), the results provided here have some limitations. Stiglbauer et al. (2013), who recently conducted a survey of herd management practices on organic and conventional dairy farms in the United States, including the Northeast, had a similarly moderate response rate (192 organic farms, $20 \%$ response rate) despite multiple follow-up reminders and a data set that included organic dairy farms in Wisconsin and Oregon. In a study of farmer response rates to surveys, Pennings et al. (2002) determined that an initial response rate ranging from 12 to $35 \%$ is typical for mail surveys. Thus, our estimated response rate of 15 to $19 \%$ falls within this range, and is consistent with studies in which the survey methods do not include follow-up reminders to prospective participants (Dillman, 2007).

\section{Demographic and Descriptive Data}

The descriptive statistical results pertaining to herd profiles and dairy management practices (Table 1) obtained from our survey are consistent with the regional findings of others (McBride and Greene, 2009; Stiglbauer et al., 2013), suggesting there is validity to the current survey despite the moderate response rate. Specifically, respondents indicated that they managed herds ranging from 12 to 450 cows and operated farms ranging from 5 to 1,100 acres, but averaging 309 acres. Overall, the farms milked an average of 57 cows, which is in agreement with the findings of McBride and Greene (2009), who reported an average herd size of 53 milking cows per farm for organic dairies in the Northeast. Organic dairy herd sizes, however, are approximately half that of conventional dairy herds within the region (approximately 120 lactating cows per farm according to Winsten et al., 2010).

On average, farms in the Northeast have been certified organic for $7.6 \mathrm{yr}$ (minimum $1 \mathrm{yr}$; maximum 17 yr) with slight variability between regions (i.e., NEng vs. NY-PA) and among herd sizes. This statistic is perceived as being mostly economically driven, because the price premium for organic milk has averaged $\$ 6.69$ more per hundredweight than that for conventional milk (McBride and Greene, 2009). Conventional dairy farms that transitioned to organic production before mid-2006 were permitted to feed no more than $20 \%$ of conventional feeds for 9 mo before switching to $100 \%$ organic feeds for 3 mo to attain organic certification (Dimitri and Greene, 2002). This provided a good incentive for farmers to transition to organic dairy production at the time because although organic feeds are more expensive than conventional feeds, the difference in premium price for organic compared with conventional milk at that time more than offset the feed expense (McBride and Greene, 2009).

Our results showed that fewer than half of the respondents $(42 \%)$ utilized DHIA record-keeping of their herds (Table 1), which is comparable to the $46 \%$ figure obtained nationally (McBride and Greene, 2009), but 
Table 1. Demographic information (SD or percentage of total in parentheses) about organic dairy farms in the northeastern United States surveyed during the spring of 2011

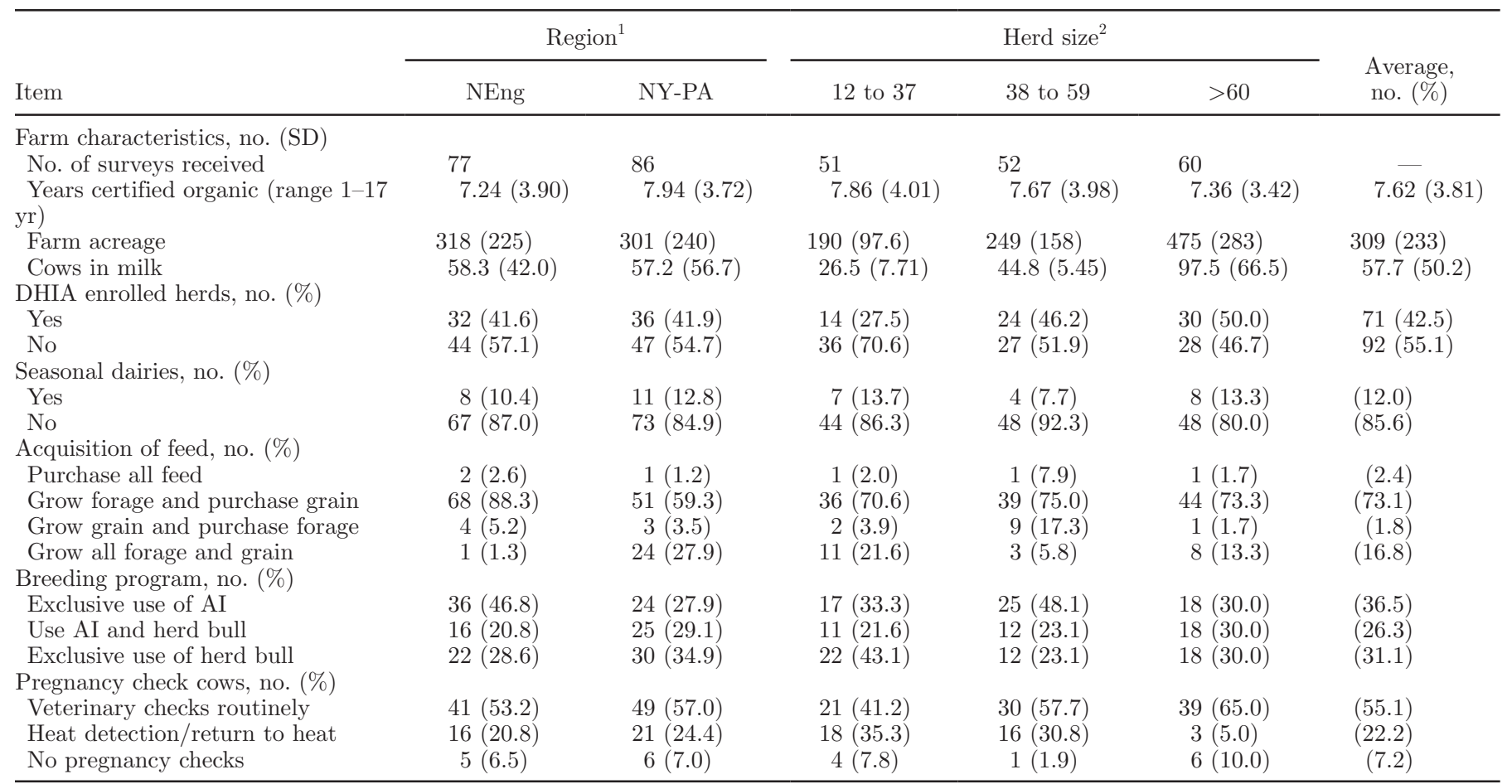

${ }^{1}$ Farms were separated in 2 main regions: NEng (New England) region with farms in Massachusetts, Maine, New Hampshire, and Vermont; and the NY-PA region with New York and Pennsylvania farms.

${ }^{2}$ Herd size was categorized as typical of small (12 to 37 cows), medium-sized (38-59 cows), and large ( $>60$ cows) farms in the northeastern United States, noting these designations provided relatively equal numbers of farms to consider when evaluating critical issues and needs assessment endpoints.

lower than that observed for conventional dairy farmers in the Northeast ( $\sim 60 \%$, according to Winsten et al., 2010). This disparity in the use of DHIA record-keeping between organic and conventional dairies has also been reported recently for farms in New York, Wisconsin, and Oregon (Stiglbauer et al., 2013). Between the NEng and NY-PA regions, the percentage of farms enrolled in the DHIA program was equivalent. Among herd sizes, however, farms with more lactating cows are more likely to enroll in this program $(27.5 \%$ with 12 to 37 cows; $46.2 \%$ with 38 to 59 cows; and $50 \%$ with $>60$ cows). These observations suggest that although herd management and herd health practices (i.e., as measured by DHIA enrollment) on organic dairies might lag behind their conventional dairy comparators, these measures are viewed by organic dairy farmers as offering an economic advantage with larger herd sizes.

Despite the relatively short growing season in the Northeast (typically from April to October), which would be conducive to seasonal operations, the majority of organic dairy farmers $(86 \%)$ do not operate seasonal dairies (Table 1). As one might expect, most farmers (73\%; Table 1) grow their own forage but purchase grain from off-farm resources, which is consistent with
McBride and Greene (2009), who showed that $71 \%$ of northeastern organic dairy farmers typically grow more than half of their animal feed, particularly forages via stored feed (e.g., baleage, haylage, silage) and pasture. These findings were not surprising considering the mandate of the National Organic Program Pasture Rules, which require ruminants to consume at least $30 \%$ of their total DMI from pastures grazed for a minimum of $120 \mathrm{~d}$ during the grazing season to maintain organic certification. Organic farmers feed approximately half as much grain as conventional farms (Richert et al., 2013a), and a relatively high percentage of respondent farmers $(73.1 \%)$ rely on purchased grain for feeding. Unfortunately, this scenario places additional economic pressure on farmers because purchased feeds account for approximately $36 \%$ of the total cash expenses of organic dairy farms in northeastern states such as Maine and Vermont (Dalton et al., 2008).

With respect to animal reproduction, $37 \%$ of all the respondents indicated that they bred cows exclusively using AI and another $26 \%$ used AI followed by cleanup bulls. Thus, the cumulative use of AI $(63 \%)$ in the current assessment was less than the $89 \%$ use reported for conventional herds in the Northeast (Winsten et al., 
$2010)$ and the $76 \%$ use reported for organic dairy herds nationally (McBride and Greene, 2009). The prominent use of a herd bull as an exclusive method for breeding, especially among small farms of 12 to 37 cows (43\%; Table 1), was unexpected yet comparable to a recent study of organic dairy herds in New York, Wisconsin, and Oregon (Richert et al., 2013b). For pregnancy detection, a slight majority of organic dairy farmers in the Northeast (55\%) rely on routine veterinary checks, but the remainder either observe cows for return to estrus or do not check for pregnancy at all (Table 1).

Understanding these demographics of organic dairy farms within the region is underscored by the fact that $97 \%$ of the organic dairy farms in the Northeast have fewer than 100 cows (McBride and Greene, 2009). All of the respondent farms with fewer than 20 cows (12 farms) indicated that they have been shipping certified organic milk for $4 \mathrm{yr}$ or more. These represent the small family farms with masked costs due to unpaid labor (i.e., family members), which are common in the Northeast and rely on diversified production as alluded to previously by others (Dalton et al., 2008; McBride and Greene, 2009).

\section{Identified Challenges}

Based upon insight obtained from the focus group interviews, the survey questionnaire used in this study asked farmers to indicate critical issues that were a challenge to them in 3 broad categories: (1) business management and marketing; (2) certification requirements and production; and (3) and animal nutrition, health, and reproduction (Supplemental File B; http:// dx.doi.org/10.3168/jds.2013-6690). In addition, farmers were asked to rate the importance of several research and educational topics. Results of the answers are summarized in Tables 2 and 3, in order of priority within each category. Differences between the NEng and NY-PA regions, and among herd sizes of 12 to 37, 38 to 59 , and $>60$ cows, when illustrative, are described throughout the text.

Business Management and Marketing Challenges. Not surprisingly, $85 \%$ of the respondents indicated a steady, fair milk price to be a challenge for them, ranking it as the highest priority (Table 2). Although organic milk has received a generally stable market price in recent years (between $\$ 0.64$ and $\$ 0.68$ per $\mathrm{kg}$ of milk from 2006 to 2012), the costs of organic grain have increased substantially (from $\$ 380 / \mathrm{t}$ in 2006 to $\$ 720 / \mathrm{t}$ in 2012 for mixed grain; USDA-AMS, 2013; USDA-ERS, 2013). This decline in profit margins for organic dairy farmers is most likely why they perceive the milk price as not fair. This challenge was similar between regions, but was identified as a greater chal- lenge for farms consisting of 38 to 59 cows $\left(\chi^{2}=9.20\right.$, $P<0.01)$ compared with other herd sizes. Under these circumstances, only $10 \%$ of organic farms with fewer than 50 cows would be expected to generate positive returns above total economic costs, and only a fourth of these would cover short-term operating costs such as equipment repairs (McBride and Green, 2009).

Other business management and marketing challenges identified included the lack of local access to USDA-inspected slaughter facilities and issues pertaining to direct milk sales (including the sale of milk to local customers and through farmers markets). Responses were, in general, equally distributed among these topics. However, farmers within the NEng region, in particular, indicated a greater challenge with direct sales of milk and milk products than farmers from the NY-PA region $\left(\chi^{2}=13.2, P<0.001\right)$, which could be attributed to a variety of factors such as issues with local regulations, consumer demand, or transportation costs. Others have documented that the relatively small-scale, multi-functional operations of the NEng region rely heavily upon community-based marketing strategies and cooperatives (Thilmany et al., 2013).

Certification Requirements and Production Challenges. Organic dairy farmers within the Northeast did not convey that certification requirements and procedures posed particular challenges (Table 2). Staying compliant with the recently enacted pasture requirements was not a difficulty, although farmers in the NY-PA region expressed greater concerns than those in the NEng region about the level of knowledge and experience of local certifiers who enforce the organic dairy certification requirements $\left(\chi^{2}=8.81, P<0.01\right)$. Farms certified organic for $<4$ yr were more concerned with level of knowledge and experience of local certifiers compared with farms certified for a longer time $\left(\chi^{2}=6.12, P=0.01\right)$. Some of these sentiments were also evident during the focus group interviews. It would appear that some consistency in training of, and expectations by, organic certifiers within the region is needed to alleviate these concerns.

Animal Nutrition, Health, and Reproduction Challenges. Similar to certification, no single topic pertaining to organic nutrition or grazing emerged as the highest priority among respondents (Table 2). This trend was consistent with the focus group interviews, wherein participants indicated to the facilitator that they had heard all they needed about pasture management and did not perceive the need for further help with this topic. Conversely, estimating and recording DMI for animals on pasture did constitute a challenge for most farmers $(76 \%$; Table 2), indicating a crossover challenge between organic certification and nutrition or grazing needs. 
Table 2. Ranking of critical issues in business management and marketing, certification requirements and procedures, and animal nutrition, health and reproduction by organic dairy farmers in the northeastern United States (Massachusetts, Maine, New Hampshire, New York, Pennsylvania, and Vermont) surveyed during the spring of 2011

\begin{tabular}{|c|c|c|c|c|c|}
\hline Critical issue & \multicolumn{5}{|c|}{$\operatorname{Rank}^{1}$} \\
\hline \multicolumn{6}{|l|}{ Business management and marketing } \\
\hline Ensuring a steady, fair price for milk & 26.8 & 32.9 & 25.0 & 14.0 & 1.2 \\
\hline Regulations on raw milk & 32.1 & 17.9 & 11.5 & 25.0 & 13.5 \\
\hline Lack of access to USDA-inspected slaughter facility & 20.1 & 29.6 & 14.5 & 23.3 & 12.6 \\
\hline Ability to sell to local customers & 14.9 & 26.6 & 22.1 & 24.7 & 11.7 \\
\hline Developing new products & 10.2 & 24.2 & 19.7 & 20.4 & 25.5 \\
\hline Diversifying income through value-added products & 9.5 & 25.3 & 24.7 & 18.4 & 22.2 \\
\hline \multicolumn{6}{|l|}{ Certification requirements and procedures } \\
\hline Record keeping for DMI for animals on pasture & 21.2 & 29.1 & 26.1 & 21.2 & 2.4 \\
\hline Report DMI & 14.5 & 25.0 & 32.2 & 26.3 & 2.0 \\
\hline Staying compliant with new pasture access regulations & 11.7 & 21.5 & 25.8 & 40.5 & 0.6 \\
\hline Managing pastures & 3.2 & 31.0 & 39.9 & 25.3 & 0.6 \\
\hline Dry cow nutrition & 3.2 & 19.2 & 36.5 & 39.7 & 1.3 \\
\hline Controlling flies & 26.3 & 32.7 & 30.1 & 10.3 & 0.6 \\
\hline Controlling mastitis & 10.2 & 35.0 & 36.3 & 17.8 & 0.6 \\
\hline Treating pneumonia & 14.2 & 23.2 & 28.4 & 32.3 & 1.9 \\
\hline Getting cows bred back timely & 6.4 & 26.1 & 36.3 & 30.6 & 0.6 \\
\hline Keeping calves healthy & 5.2 & 24.5 & 45.2 & 24.5 & 0.6 \\
\hline High culling rates & 1.9 & 19.5 & 25.3 & 51.9 & 1.3 \\
\hline Cystic ovaries & 3.9 & 9.8 & 43.8 & 40.5 & 2.0 \\
\hline Heat detection & 1.9 & 13.5 & 35.9 & 47.4 & 0.6 \\
\hline
\end{tabular}

${ }^{1}$ The results of 163 surveys were analyzed and ranked according to challenges identified previously in focus group interviews. The percentage of total respondents is shown, with challenges itemized categorically in priority order from highest to lowest; ranks were based on a Likert scale from 0 to 4 , where $0=$ do not know, $1=$ not a challenge, $2=$ minor challenge, $3=$ some challenge, and $4=$ great challenge.

Table 3. Ranking of critical research and educational needs by organic dairy farmers in the northeastern United States (Massachusetts, Maine, New Hampshire, New York, Pennsylvania, and Vermont) surveyed during the spring of 2011

\begin{tabular}{|c|c|c|c|c|c|}
\hline \multirow[b]{2}{*}{ Needs of organic dairy farmers } & \multicolumn{5}{|c|}{$\operatorname{Rank}^{1}$} \\
\hline & $\begin{array}{c}\text { Very } \\
\text { important }\end{array}$ & $\begin{array}{c}\text { Moderately } \\
\text { important }\end{array}$ & $\begin{array}{l}\text { Slight } \\
\text { need }\end{array}$ & $\begin{array}{l}\text { No } \\
\text { need }\end{array}$ & $\begin{array}{l}\text { Do not } \\
\text { know }\end{array}$ \\
\hline \multicolumn{6}{|l|}{ Needs for additional research } \\
\hline Efficacy of organic treatments for mastitis & 35.5 & 31.6 & 25.2 & 5.2 & 2.6 \\
\hline Field testing new organic treatment products & 28.4 & 36.8 & 17.4 & 7.1 & 10.3 \\
\hline Development of value added markets for organic milk & 33.6 & 29.6 & 20.4 & 6.6 & 9.9 \\
\hline \multicolumn{6}{|l|}{ Needs for additional educational programs } \\
\hline Veterinary training in organic treatments & 44.6 & 33.8 & 12.1 & 7.6 & 1.9 \\
\hline Direct marketing opportunities & 25.8 & 31.1 & 19.2 & 15.2 & 8.6 \\
\hline Business management skills & 19.1 & 32.5 & 33.1 & 12.7 & 2.5 \\
\hline Ration balancing & 14.3 & 36.4 & 35.1 & 11.7 & 2.6 \\
\hline Estimating DMI on pasture & 12.8 & 37.8 & 32.7 & 14.1 & 2.6 \\
\hline Liaison/intermediary with organic certifiers & 12.9 & 27.9 & 22.4 & 21.1 & 15.6 \\
\hline
\end{tabular}

${ }^{1}$ The results of 163 surveys were analyzed and ranked according to research and educational needs identified previously in focus group interviews. The percentage of total respondents is shown, with research and educational needs grouped separately but itemized in priority order from highest to lowest; ranks were based on a Likert scale from 0 to 4 , where $0=$ do not know, $1=$ no need, $2=$ slight need, $3=$ moderately important need, and 4 = very important need. 
Unequivocally, integrated pest management (i.e., fly control) was deemed the highest priority animal health challenge for organic dairy farmers in the Northeast (89\% respondents; Table 2). Moreover, herd sizes of 12 to 37 cows had greater problems with nuisance flies than others $\left(\chi^{2}=6.46, P<0.05\right)$. Controlling mastitis was a challenge or somewhat of a challenge for $81.5 \%$ of respondent farmers (Table 2), placing it as the second major health concern, with no significant difference between regions or among herd sizes. This is in accordance with Sato et al. (2005), Pol and Ruegg (2007), and Valle et al. (2007), who reported lower rates of clinical mastitis for organic herds compared with conventional herds, and herds implementing rotational grazing management having lower SCC than herds managed by continuous grazing or kept in confinement housing. Mammary gland infection and clinical mastitis, however, may be an underestimated concern on organic farms. Others have noted philosophical differences in the detection and perception of cure of clinical mastitis between organic and conventional farmers (Pol and Ruegg, 2007). Those authors also suggested that mastitis is perhaps more recognized on conventional farms than organic farms because extensive treatment options exist. Most recently, Richert et al. (2013a) confirmed that organic farmers identified and reported lower rates of clinical mastitis compared with conventional farmers, and they cited reports in which the difference might be attributed to genetic influences, inconsistent record-keeping by organic farmers, and a variety of environmental factors.

No other animal health or reproductive issues arose as a particular challenge for the farmers although, as noted above, the use of a herd bull might have obscured any immediate or future reproductive challenges.

\section{Research and Educational Programs}

Potential topics for additional research and educational programs identified by the focus group interviews and then prioritized by the survey are summarized in Table 3. When asked specifically about research topics important to northeastern organic dairy farmers, $67 \%$ of respondents indicated that research into the efficacy of organic mastitis treatments was a moderately to very important need, and almost as many respondents (65\%) indicated as important the need for field testing of new organic products in general. Farms certified organic for $\geq 4 \mathrm{yr}$ indicated field testing of new organic products to be of great importance compared with farms with $<4$ yr of certification $\left(\chi^{2}=4.05, P<0.05\right)$. No regional or herd size differences in these topics were evident $(P$ $>0.05$ ), suggesting that these research areas are broad needs for organic dairy farmers in the Northeast re- gion, independent of location and herd size. Additional research topics deemed important included the further development of value-added products to increase profitability (63\% respondents) and improved methods for organic forage production (59\% respondents).

Consistent with the findings of the focus group interviews, a very high educational need identified by the survey was additional training of veterinarians in the use of organic treatments. Ninety percent of respondents indicated that training of veterinarians to prescribe organic treatments was a slight to very important educational need (Table 3), with no further differences attributed to region or herd size $(P>0.05)$. Further education about direct marketing opportunities was also identified as a moderate to very important need for $56 \%$ of respondents. This latter need is consistent with the historic role that New England states have had in being among the top 10 states nationally in direct-to-consumer food marketing as a share of total agricultural sales (Diamond and Soto, 2009). Direct marketing is arguably a unique niche for agriculture in the Northeast and organic dairy farmers seek additional opportunities to participate.

\section{Limitations}

Acknowledging that the moderate response rate to the survey is a limiting factor to broad interpretation of these results, our findings nevertheless provide insight about current and emerging needs of the organic dairy industry in the Northeast. Certainly, the consistency in the demographic data presented here and those reported previously (McBride and Greene, 2009; Stiglbauer et al., 2013) provide some assurance of rigor to our sampled population. We did discover, however, instances in which some of the survey findings did not substantiate the focus group responses. These discrepancies suggest that there are additional items of importance to organic dairy farmers that might not have been addressed at all by the survey. Input from supporters of the northeastern organic dairy industry, such as milk processors, veterinarians, organic certifiers, and feed dealers, was also not part of this study. Our collective findings do provide, however, an important first step toward the development of future in-depth research and educational efforts that will benefit the organic dairy industry in the Northeast.

\section{CONCLUSIONS}

The growing interest and expansion of organic dairy production in the northeastern United States has prompted university researchers and extension educators to focus their efforts on the issues most critical 
to this industry. The results of the focus group interviews and survey questionnaire presented here are an important first step. Further inquiry will be critical to developing relevant and effective research agendas that can provide science-based answers to questions about economic opportunities to increase profitability, methods to enhance forage production, and the utility of certain organic treatments. In addition, high-quality educational programming tailored for farmers and other stakeholders by extension educators should be developed, working closely with the industry to ensure that research findings and best practices are shared appropriately, providing farmers with the skills and knowledge they need to be successful.

\section{ACKNOWLEDGMENTS}

This project was supported by the USDA-NIFAOrganic Agriculture Research and Extension Initiative program (grant \#2010-51300-21263) and by the Northeastern Regional Association (NERA) of State Agricultural Experiment Station Directors (grant \#NE1005). It is scientific contribution number 2499 from the New Hampshire Agricultural Experiment Station. We thank Paul Tsang (University of New Hampshire), Robert Parsons (University of Vermont Extension), Richard Kersbergen (University of Maine Extension), A. Fay Benson (Cornell University Extension), and Peter Miller (CROPP Cooperative and Organic Valley) for their contributions to the organization and implementation of the focus group interviews. We also thank Ed Maltby (NODPA executive director) for assisting with the distribution of the survey to NODPA members, and Lisa McCrory (NODPA News editor) for informing the organic dairy community about the upcoming survey in the NODPA news. Portions of this work were presented previously at the 2012 Northeast Organic Research Symposium sponsored by the Northeast Organic Farming Association of New York (NOFA-NY) Winter Conference held January 19-20, 2012, in Saratoga Springs, New York.

\section{REFERENCES}

Creswell, J. W. 1998. Qualitative Inquiry and Research Design: Choosing Among Five Traditions. Sage Publications, Thousand Oaks, CA.

Dalton, T. J., R. Parsons, R. Kersbergen, G. Rogers, D. Kaupilla, L. McCrory, L. A. Bragg, and Q. Wang. 2008. A comparative analysis or organic dairy farms in Maine and Vermont: Farm financial information form from 2004 to 2006. Bulletin 851. Maine Agriculture and Forest Experiment Station, University of Maine, Orono.

Diamond, A., and R. Soto. 2009. Facts on Direct-to-Consumer Food Marketing: Incorporating Data from the 2007 Census of Agriculture. Agricultural Marketing Service, US Department of Agriculture, Washington, DC. 10.9752/MS035.05-2009.

Dillman, D. A. 2007. Mail and Internet Surveys: The Tailored Design Method. 2nd ed; 2007 update. John Wiley \& Sons Inc., New York, NY.
Dimitri, C., and C. Greene. 2002 Recent growth patterns in the U.S. Organic Foods Market. Agriculture Information Bulletin Number 777. US Department of Agriculture, Economic Research Service, Washington, DC.

Groves, R. M., F. J. Fowler, M. P. Couper, J. M. Lepkowski, E. Singer, and R. Tourangeau. 2004. Survey Methodology. John Wiley \& Sons Inc., Hoboken, NJ.

Marshall, C., and G. B. Rossman. 1999. Designing Qualitative Research. 3rd ed. Sage Publications, Thousand Oaks, CA.

McBride, W. D., and C. Greene. 2009. Characteristics, costs, and issues for organic dairy farming. Economic Research Report Number 82. US Department of Agriculture, Washington, DC.

Miller, J. J., and D. P. Blayney. 2006. Dairy Backgrounder, LDPM-145-01. Economic Research Service, US Department of Agriculture, Washington, DC.

Pennings, J. M. E., S. H. Irwin, and D. L. Good. 2002. Surveying farmers: A case study. Rev. Agric. Econ. 24:266-277.

Pol, M., and P. L. Ruegg. 2007. Treatment practices and quantification of antimicrobial drug usage in conventional and organic dairy farms in Wisconsin. J. Dairy Sci. 90:249-261.

Richert, R. M., K. M. Cicconi, M. J. Gamroth, Y. H. Schukken, K. E. Stiglbauer, and P. L. Ruegg. 2013a. Risk factors for clinical mastitis, ketosis, and pneumonia in dairy cattle on organic and small conventional farms in the United States. J. Dairy Sci. 96:42694285 .

Richert, R. M., K. M. Cicconi, M. J. Gamroth, Y. H. Schukken, K. E. Stiglbauer, and P. L. Ruegg. 2013b. The role of the veterinarian on organic and conventional dairy farms. J. Am. Vet. Med. Assoc. 242:1732-1743.http://dx.doi.org/10.2460/javma.242.12.1732

Rossi, P. H., M. W. Lipsey, and H. E. Freeman. 2004. Evaluation: A Systematic Approach. 7th ed. Sage Publications, Thousand Oaks, CA.

Sato, K., P. C. Bartlett, R. J. Erskine, and J. B. Kaneene. 2005. A comparison of production and management between Wisconsin organic and conventional dairy herds. Livest. Prod. Sci. 93:105-115.

Seidman, I. 1998. Interviewing as Qualitative Research: A Guide for Researchers in Education and the Social Sciences. Teachers College Press, New York, NY.

Stiglbauer, K. E., K. M. Cicconi-Hogan, R. Richert, Y. H. Schukken, P. L. Ruegg, and M. Gamroth. 2013. Assessment of herd management on organic and conventional dairy farms in the United States. J. Dairy Sci. 96:1290-1300.

Taylor-Powell, E., and C. Hermann. 2000. Collecting Evaluation Data: Surveys. Program Development and Evaluation. University of Wisconsin-Extension, Madison.

Thilmany, D., D. Conner, K. Curtis, K. Liang, K. Mulik, J. O'Hara, M. Sullins, and T. Woods. 2013 Researching market and supplychain opportunities for local food systems: Setting priorities and identifying linkages. J. Agric. Food Syst. Community Dev. http:// dx.doi.org/10.5304/jafscd.2013.034.018.

USDA-AMS (US Department of Agriculture-Agricultural Marketing Service). 2013. Market news and transportation data. Accessed May 2013. http://www.ams.usda.gov/AMSv1.0/ams. fetch TemplateData.do?template $=$ TemplateW\&navID $=$ RN2L1 Feedstuffs\&rightNav1 $=$ RN2L1Feedstuffs\&topNav $=\&$ leftNav $=$ MarketNewsAndTransportationData\&page=SearchFeedstuffs Reports\&resultType $=\&$ acct $=l$ smn .

USDA-ERS (US Department of Agriculture-Economic Research Service). 2013. Organic production. Accessed May 2013. http://www. ers.usda.gov/data-products/organic-production.aspx.

USDA-NASS (US Department of Agriculture-National Agricultural Statistics Service). 2012. Quick stats. Accessed November 2012. http://www.nass.usda.gov/Quick_Stats/.

Valle, P. S., G. Lien, O. Flaten, M. Koesling, and M. Ebbesvik. 2007. Herd health and health management in organic versus conventional dairy herds in Norway. Livest. Sci. 112:123-132.

Winsten, J. R., C. D. Kerchner, A. Richardson, A. Lichau, and J. M. Hyman. 2010. Trends in the Northeast dairy industry: Large-scale modern confinement feeding and management-intensive grazing. J. Dairy Sci. 93:1759-1769. 